formed by trained nurses, widespread open access endoscopy cannot be far away; some districts already have an open access service staffed by doctors. ${ }^{6}$ Hopefully, however, all new open access services will be carefully assessed before they become widespread: the definition of a successful service is one in which the test replaces the need for a specialist opinion. The more a test can be reported in simple numerical terms the more suited it is to open access; the more a report depends on opinion the more important that it is made in the light of a clinical assessment of the patient. One of the problems of both open access exercise testing and echocardiography is couching reports in terms that general practitioners can use in patient management. As with all open access investigations the key to optimal use is strict guidelines agreed between specialists and general practitioners.

In general, investigations are simultaneously becoming more sophisticated and yet simpler to carry out. If open access goes too far there is a danger that general practitioners will find themselves weighed down by data that they find hard to interpret. General practitioners who seek an opinion need to refer their patients to a clinic, not simply to send them to hospital for a test. Specialists must not simply be gatekeepers for investigations; it is their opinions about clinical problems that make them useful.

J R HAMPTON

Cardiovascular Medicine,

Professor of cardiology

University Hospital,

Nottingham NG7 2UH

A R BARLOW

East Leake Health Centre, General practitioner

Loughborough,

Leicestershire LE12 6JG

1 McClements BM, Campbell NPS, Cochrane D, Stockman S. Direct access exercise electrocardiography: a new service that improves the management of suspected ischaemic heart disease in the community. Br Hear o 1994;71:531-5.

2 Bramble MG, Cooke WM, Corbett WA, Cann PA, Clarke D, Contractor B, et al. Organising unrestricted open access gastroscopy in South Tees. Gut 1993;34:422-7.

Francis CM, Caruana L, Kearney P, Love M, Sutherland GR, Starkey IR, et al. Open access echocardiography in management of heart failure in community. $B M f 1995 ; 310: 634-6$.

Wheeldon NM, Macdonald TM, Flucker CJ, McKendrick AD, McDevitt DG, Struthers AD. Echocardiography in chronic heart failure in the community. Of Med 1993;86:17-23.

Echocardiography in chronic heart failure in the community. Qf Med 1993;86:17-23.
Clarke KW, Gray D, Hampton JR. Evidence of inadequate investigation and treatment of patients Clarke KW, Gray D, Hampton JR. Evidence of
with heart failure. Br Heart $f 1994 ; 71: 584-7$.

6 Kerrigan DD, Brown SR, Hutchinson GH. Open access gastroscopy: too much to swallow? $B M \mathcal{F}$ 1990:300:374-6

\title{
Advance directives
}

\section{Like a will, everybody should have one}

The moral duty to respect autonomy is now an established part of good clinical practice. ${ }^{1}$ Patients have the legal right to decide whether or not they will allow themselves to be touched for the purposes of medical treatment. Consequently, they also have the right to refuse proposed treatments, even when doctors believe that such treatments are in their best interests. ${ }^{2}$ The most dramatic example of such refusal is the rejection of life saving treatment.

Doctors often find it hard to accept that patients might prefer death to clinical care, especially when they are incompetent and cannot speak for themselves. If doubts exist about what a competent patient wants or needs, they can be discussed when they arise. Since incompetence precludes such debate, the duty of care must be guided by consideration of the patient's best interest. ${ }^{3}$ Where a clear consensus exists about the positive effects of treatment this provides an appropriate basis for clinical care. But when such agreement does not exist doctors may face intolerable moral and legal indeterminacy.

The classic cases of such indeterminacy usually concern decisions not to treat patients. It is now accepted that circumstances exist in which not providing lifesaving treatment is professionally and legally acceptable. ${ }^{4}$ Examples include those in which treatment is futile or patients are irreversibly close to death or have extreme brain damage. Yet doctors are rightly conservative about how these situations should be interpreted. Mistakes about non-treatment cannot be corrected and might give rise to legal action.

This conservatism has led to incompetent patients sometimes being kept alive in circumstances when, had they been competent, they would have preferred to die. The consequences have been distressing for relatives, doctors, and sometimes the patients themselves.

Against this background comes Mental Incapacity, published last week by the Law Commission. ${ }^{5}$ The commission endorses the principle of what it calls "advance statements about health" (that is, advance directives or living wills) and recommends supporting legislation. There is little doubt that, given recent developments in case law, such statements already have legal force in Britain. ${ }^{6}$ To remove any possibility of ambiguity, however, the commission argues that statute law should clearly stipulate the means by which competent people of 18 and over can exert control over medical treatment if they become incompetent patients.

Of course, this right to consent does not extend to determining either the type or amount of treatment to be offered. ${ }^{7}$ Though the views of patients should be taken into account, such provision is ultimately a matter of clinical and managerial discretion. Consequently, the most important conclusion of the commission concerns what it calls "advance refusals"-statements that prohibit life sustaining treatments should the patient become incompetent.

The commission argues that such refusals should

- Be made by people competent to do so-able to understand, retain, and act on the information on which the refusal is based

- Be presumed to be valid if signed and witnessed

- Be revocable if the patient is competent to revoke them

- Explicitly state the author's awareness that death might or will be the result of the refusal

- Be suspended if being assessed by a court for validity

- Not preclude the provision of basic care, defined as the maintenance of bodily cleanliness, relief of sustained and serious pain, and the provision of oral nutrition and hydration

- Not be deliberately ignored, such action being a criminal offence.

These are sensible proposals and should be enacted in law. Doctors will then be more likely to acquaint themselves with advance refusals and to discuss with patients any options concerning non-treatment. ${ }^{8}$ The quality of care for incom- 
petent patients who have made such refusals will increase as a result. Their dignity will be preserved because the autonomy that they once had will continue to be respected. Equally, the quality of life of their doctors should also improve because of their knowledge that they are not striving futilely to sustain a life of a sort unwanted by the person to whom it once belonged.

One problem with the Law Commission's proposals is its unwillingness to commit itself to a standardised form of advance refusal. Yet if forms are to be used confidently by clinicians-especially in emergencies-it is important that they are of uniform appearance and structure, for their validity can always be contested. To be valid, a will bequeathing property must obey formal rules specified by statute. Why should the same not apply to advance refusals?

To be fair, the commission advocates the creation of a code of practice that could go into further detail of this kind, one which might be given more formal status by the secretary of state. The importance of this cannot be overestimated. Many advance refusals will conflict with clinical intuitions, which in any other context would be unconstrained. For this reason alone, if advance refusals are to be successful, the clarity of their form and content will be essential. Of equal importance will be the education and training of doctors.

The Law Commission has underlined the people's rights to plan their medical destiny and the need for legislation to protect these rights. Other organisations-the BMA is a good example-are working to the same end. Practitioners should do the same through dialogue with their patients and through formulating an advance refusal of their own.

LEN DOYAL Reader in medical ethics

London Hospital and St Bartholomew's Medical Colleges,

University of London,

London E1 2AD

1 British Medical Association. Medical ethics today. London: BMA, 1993

2 Brazier M. Medicine, patients and the law. Harmondsworth: Penguin, 1992:73-93.

3 F $v$ West Berkshire Health Authority (1989) 2 All ER 545, HL.

Doyal L, Wilsher $\mathrm{D}$. Withholding and sustaining treatment from elderly people: guidelines. $B M \varsubsetneqq$ 1994;308:1689-92.

5 Law Commission. Mental incapacity. London: HMS0, 1995.

6 Robertson G. Making an advance directive. $B M \mp 1995 ; 310: 236-8$.

7 Kennedy I, Grubb A. Medical text and materials. London: Butterworths, 1994:1278.

8 Ashby M, Wakefield M, Beilby J. General practitioners' knowledge and use of living wills. $B M \Im$ 1995;310:230.

\title{
Oregon's plans to legalise suicide assisted by a doctor
}

\author{
How much more open will the practice become?
}

Oregon voters' approval of Ballot Measure 16 in last November's election marked the first time that suicide assisted by a doctor had been legalised anywhere in the world. Although an injunction currently bars the law, its passage by the electorate suggests that American attitudes towards suicide assisted by a doctor are shifting gradually towards acceptance. ${ }^{1}$ Surveys suggest that the attitudes of American doctors ${ }^{2-5}$ are also shifting - as they are in many other countries.

If the injunction is lifted the new law in Oregon will allow a primary care doctor to prescribe a lethal dose of drugs for a terminally ill adult patient who asks for it in order to give himself or herself an overdose. The doctor has the right to decline. The patient must be a resident of Oregon who is competent, informed, and expected to die within six months. A second doctor must confirm the prognosis. The patient must make two oral requests, separated by a 15 day waiting period, and one written request. If the doctor suspects that the patient has a mental disorder affecting judgment the doctor must refer him or her to a mental health professional. The doctor must ask the patient to disclose his or her intentions to family members, although the patient is not required to do so. Insurance companies may not withhold death benefits when patients comply with the law. Doctors who act in good faith with the law are protected from professional discipline and legal liability. Doctors must report participation to the state health division. ${ }^{6}$

During the election campaign, debate was highly polarised and the issue was largely framed in terms of religion and patients' rights. The Catholic church and most Protestant denominations strongly opposed legalisation on moral grounds. National Right-to-Life, an organisation that is strongly against abortion, was also active in the campaign against Ballot Measure 16. The American Medical Association officially opposed the measure and publicly criticised its state affiliate, the Oregon Medical Association, for failing to take a stand against it.
On 8 November $51 \%$ of Oregonians voted in favour of the measure and $49 \%$ voted against it. One day before the law was to go into effect on 8 December two doctors and several terminally ill patients, represented by a lawyer from national Right-to-Life, filed a class action lawsuit claiming that the law discriminates against terminally ill patients and people with religious objections. ${ }^{7} \mathrm{~A}$ federal judge has issued a preliminary injunction pending a trial to review the constitutional questions. Both sides have indicated that the decision will be appealed against regardless of the outcome. This suggests that the court process may continue for quite a long time and may reach the level of the United States Supreme Court.

Although the legal fate of the statute has not been decided, its approval by voters raises several issues. Although anecdotal reports confirm that suicide is sometimes assisted by doctors in the United States, this is illegal. ${ }^{2}$ Would legalisation in Oregon bring the practice into the open? Several factors suggest that, even in Oregon, doctors might continue to help patients to die in secrecy. Despite legalisation, if suicide assisted by a doctor remains contrary to professional codes then doctors who openly participate may risk ostracism by colleagues. Catholic health care systems in Oregon have already announced that they will not offer suicide assisted by a doctor and that they will discipline doctors who participate within their facilities.

\section{Threats from "right to life" activists}

Doctors might also be reluctant to write lethal prescriptions openly, even if it was legal, because of concerns for both patients' privacy and their own. For years the American antiabortion movement has drawn negative public attention to doctors who perform abortions, although abortions are accepted medical practice in the United States. Antiabortion activists often demonstrate outside doctors' offices, clinics, and homes. Recent shootings of doctors and innocent 